\title{
Gaze-finger movement analysis with an eye-head biomechanical model
}

\author{
Ronald Josef Zvonimir Dangel*, Catherine Disselhorst-Klug
}

\begin{abstract}
In our daily life, eyes and hands are continuously in action and the evaluation of these movements has always been discussed. This paper presents an eye-head biomechanical model to explain how the movements between the eyes and finger are synchronized in a common spatial coordinate system. A robot, an eye-tracker and a movement analysis system with cameras were used to capture the head and eye movements. Head angles were calculated using the biomechanical model and a global point of gaze was encountered in relation to the object in focus. The results showed correlations between the trajectories to the point of gaze and finger when the subjects followed the trajectories of the robot, providing a quantitative evaluation of the movements.
\end{abstract}

Keywords Point of gaze, Biomechanical model, Upper extremity movements, Eye-finger movement analysis.

\section{Análise dos movimentos do dedo e do ponto focal com um modelo biomecânico dos olhos e da cabeça}

\begin{abstract}
Resumo Em nosso dia a dia os olhos e as mãos estão continuamente em ação, mas estes movimentos estão sempre sendo discutidos. Este artigo apresenta um modelo biomecânico dos olhos e da cabeça para esclarecer como os movimentos entre os olhos e o dedo são sincronizados em um sistema de coordenadas tridimensional comum. Um robô, um eye-tracker e um sistema de análise de movimento com câmeras foram usados para capturar os movimentos dos olhos e da cabeça. Os ângulos da cabeça foram calculados usando o modelo biomecânico e um ponto focal global foi encontrado em relação ao robô em movimento. Os resultados mostraram correlações entre as trajetórias do ponto focal e do dedo quando os sujeitos seguiram trajetórias do robô, proporcionando uma avaliação quantitativa dos movimentos.
\end{abstract}

Palavras-chave Ponto focal, Modelo biomecânico, Movimentos das extremidades superiores, Análise dos movimentos entre olhos e o dedo. 


\section{Introduction}

Movement is the result of the interaction of at least three factors: the central nervous system, the body and the environment. Kinetic and kinematic information are being continuously exchanged among these factors (Vercher et al., 2003). In natural circumstances, the eyes and hands produce motion across multiple actions and need to remain synchronized in time with respect to a common spatial coordinate system (Pelz et al., 2001). There are several examples to the analysis of the eye-hand movements. Gowen and Miall (2006) evaluated the drawing and tracing of simple shapes and Horstmann and Hoffmann (2005) executed choice tests when two or more equivalent objects were presented at the same time and the subject selected one to grasp. Vercher et al.(1994) presented also an investigation about the coordination between the eyes, head and hand movements. The subject was seated in front of a horizontal board where hand pointing movements were performed. A matrix of red light emitting diodes (LEDs) was incorporated into the board along a circular line with a radius of $60 \mathrm{~cm}$, centred on the vertical axis of the subject's head. The LEDs were presented randomly in different angular positions in relation to the observer's sagittal plane on the right hemi space. Eye motions were recorded by electrooculography (EOG) electrodes, head rotation by an ultrasonic device and the $(x, y)$ components of the fingertip position by a Selspot infrared system.

Such movements in relation to visual targets are controlled by different primary sensory sources while the target position is determined by the vision (Bernier et al., 2005; Lateiner and Sainburg, 2003). Evidence shows that the central nervous system generates a motor plan to accurately define the amplitude and direction of the movements in relation to a global point of gaze concerning the redundancy of the neuromuscular control (Sarlegna et al., 2003).

Therefore, eyes and hands are continuously in action and the evaluation of these movements is always being discussed due to its importance. This paper presents an eye-head biomechanical model to introduce free movements of the head and eyes providing an investigation of the gaze when the subjects follow a target in motion with the finger.

\section{Materials and Methods}

\section{Eye-head biomechanical model}

A biomechanical model of the head and eyes was developed in SimMechanics ${ }^{\mathrm{TM}}$ environment from mathematical considerations to model upper extremities proposed by Schmidt et al. (1999) and Williams et al.
(2006). SimMechanics ${ }^{\mathrm{TM}}$ is a mechanical block diagram modelling environment for the engineering design and simulation of rigid bodies and their motions using standard Newtonian laws. The upper body was divided into four rigid segments: the head, the thorax, left and right eyes. The head and thorax were defined by three non-collinear reflective markers mounted on flexible cuffs to minimize inter-marker movements. The head is assumed to be connected with the thorax by an ideal ball-and-socket joint in the neck (Figure 1).

\section{Definition of the neck joint center}

The sternoclavicular joint center located on the incisura jugularis and an additional reflective maker on the seventh cervical vertebrae $m_{c 7}$ was used to find the center of the neck joint $\vec{c}_{n}$ (Figure 2), following:

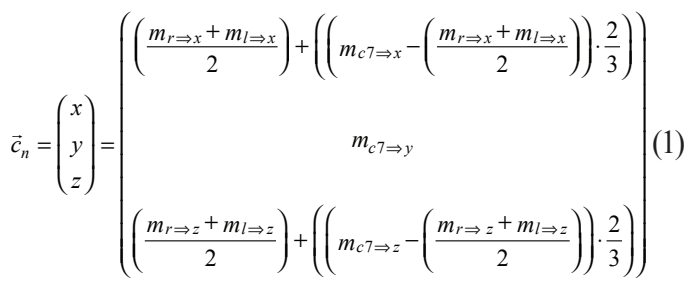

where:

- $m_{r \Rightarrow x}=$ right reflective marker position of the thorax in the $x$ direction;

- $m_{r \Rightarrow y}=$ right reflective marker position of the thorax in the $y$ direction;

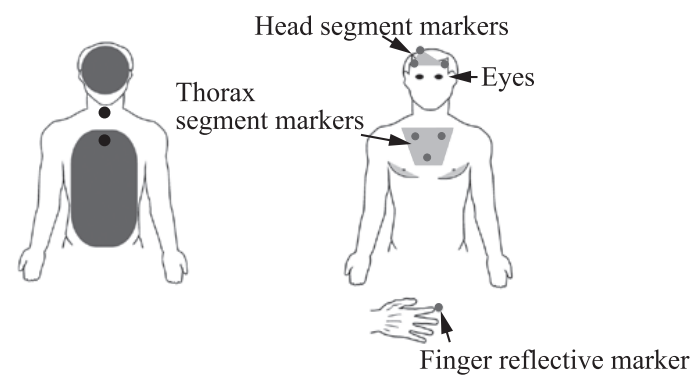

Figure 1. Left: Representation of the head and thorax, connected by an ideal ball-and-socket joint in the neck. Right: Position of the reflective markers.

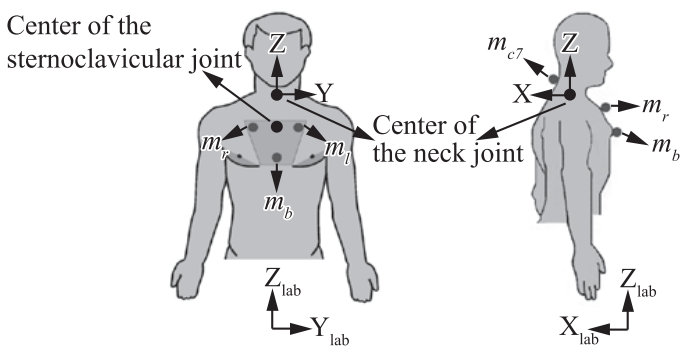

Figure 2. Center of the neck joint. 
- $m_{r \Rightarrow z}=$ right reflective marker position of the thorax in the $z$ direction;

- $m_{l \Rightarrow x}=$ left reflective marker position of the thorax in the $x$ direction;

- $m_{l \Rightarrow y}=$ left reflective marker position of the thorax in the $y$ direction;

- $m_{l \Rightarrow z}=$ left reflective marker position of the thorax in the $z$ direction;

- $m_{b}=$ bottom reflective marker position of the thorax;

- $m_{c 7 \Rightarrow x}=$ reflective marker position of the seventh cervical vertebrae in the $x$ direction;

- $m_{c 7 \Rightarrow y}=$ reflective marker position of the seventh cervical vertebrae in the $y$ direction;

- $\quad m_{c 7 \Rightarrow z}=$ reflective marker position of the seventh cervical vertebrae in the $z$ direction;

- $x=$ position of the neck joint in the $x$ direction;

- $y=$ position of the neck joint in the $y$ direction;

- $z=$ position of the neck joint in the $z$ direction.

The position of the neck center is assumed to be $2 / 3$ of the distance between the seventh cervical vertebrae marker $m_{c 7}$ and the sternoclavicular joint center in the $x$ and $z$ directions (Equation 1). In the $y$ direction, $\vec{c}_{n}$ is in the same position of the sternoclavicular joint and therefore no equations were used to correct the position of the neck joint in this direction.

\section{Segment and joint coordinate systems of the head and neck}

The coordinate system of the head is defined by using the right back, right and left front reflective markers ( $m_{r b h d}, m_{r f h d}, m_{l f h d}$ ) respectively (Figure 3 ). The axes are calculated with

$\vec{x}_{h}(t)=m_{r b h d}(t)-m_{r f h d}(t)$

$$
\vec{y}_{h}(t)=m_{l f h d}(t)-m_{r f h d}(t)
$$
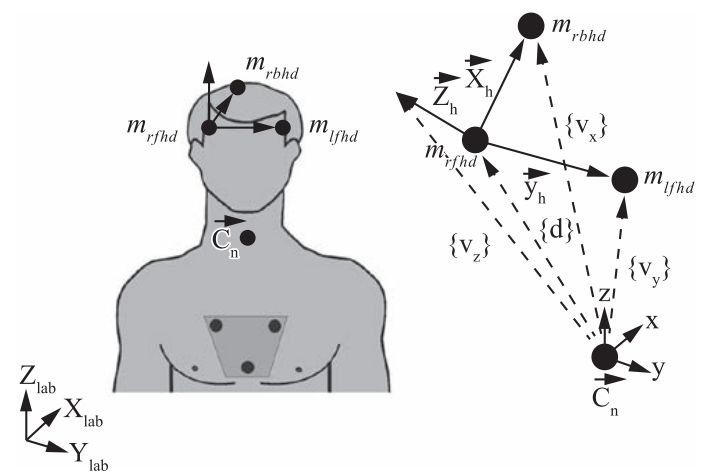

Figure 3. Segment and joint coordinate systems to the head and neck. Front view on the plane $\left(Y_{l a b}, Z_{l a b}\right)$ and lateral view on the plane $\left(X_{l a b}, Z_{l a b}\right)$.

$$
\vec{z}_{h}(t)=\vec{y}_{h}(t) \times \vec{x}_{h}(t)
$$

The three normalized unit vectors can represent the orientation of the head local coordinate system in relation to the neck center with

$\hat{x}_{h}=\frac{v_{x}-d}{\left\|v_{x}-d\right\|}$

$\hat{y}_{h}=\frac{v_{y}-d}{\left\|v_{y}-d\right\|}$

$\hat{z}_{h}=\frac{v_{z}-d}{\left\|v_{z}-d\right\|}$

The three column vectors can be combined with a $3 \times 3$ rotation matrix $\left[R_{h}\right]$, which will describe the rotational orientation of the head coordinate system by:

$\left[\begin{array}{lll}\left\{\hat{x}_{h}\right\} & \left\{\hat{y}_{h}\right\} & \left\{\hat{z}_{h} h\right.\end{array}\right]=R_{h}$

\section{Head movements}

The movements of the head are defined by the rotation matrix $\left[R_{h}\right]$ considering the rotation, flexion / extension and lateral flexion angles previously determined by the rotation between the coordinate system of the head and the translation of the neck joint center $\vec{c}_{n}$ (Figure 4), following:

$\left(\begin{array}{l}x_{h} \\ y_{h} \\ z_{h}\end{array}\right)_{\text {new }}=R_{h} \times\left(\begin{array}{l}x_{h} \\ y_{h} \\ z_{h}\end{array}\right)+\left(\begin{array}{l}x \\ y \\ z\end{array}\right)$

$\vec{c}_{n}=\left(\begin{array}{l}x \\ y \\ z\end{array}\right)$

$R_{h}=R_{\text {head }}\left(z_{h}, \omega\right) \times R_{\text {head }}\left(y_{h}, \xi\right) \times R_{\text {head }}\left(x_{h}, \vartheta\right)$

where:

$$
\begin{aligned}
& R_{\text {head }}\left(x_{h}, \vartheta\right)=\left[\begin{array}{ccc}
1 & 0 & 0 \\
0 & \cos \vartheta & -\sin \vartheta \\
0 & \sin \vartheta & \cos \vartheta
\end{array}\right] \\
& R_{\text {head }}\left(y_{h}, \xi\right)=\left[\begin{array}{ccc}
\cos \xi & 0 & \sin \xi \\
0 & 1 & 0 \\
-\sin \xi & 0 & \cos \xi
\end{array}\right] \\
& R_{\text {head }}\left(z_{h}, \omega\right)=\left[\begin{array}{ccc}
\cos \omega & -\sin \omega & 0 \\
\sin \omega & \cos \omega & 0 \\
0 & 0 & 1
\end{array}\right]
\end{aligned}
$$

After the left site multiplication with the transpose of $R_{\text {head }}(z h, \omega)$, is found:

$R_{\text {head }}\left(z_{h}, \omega\right)^{T} \times R_{h}=R_{\text {head }}\left(y_{h}, \xi\right) \times R_{\text {head }}\left(x_{h}, \vartheta\right)$ 


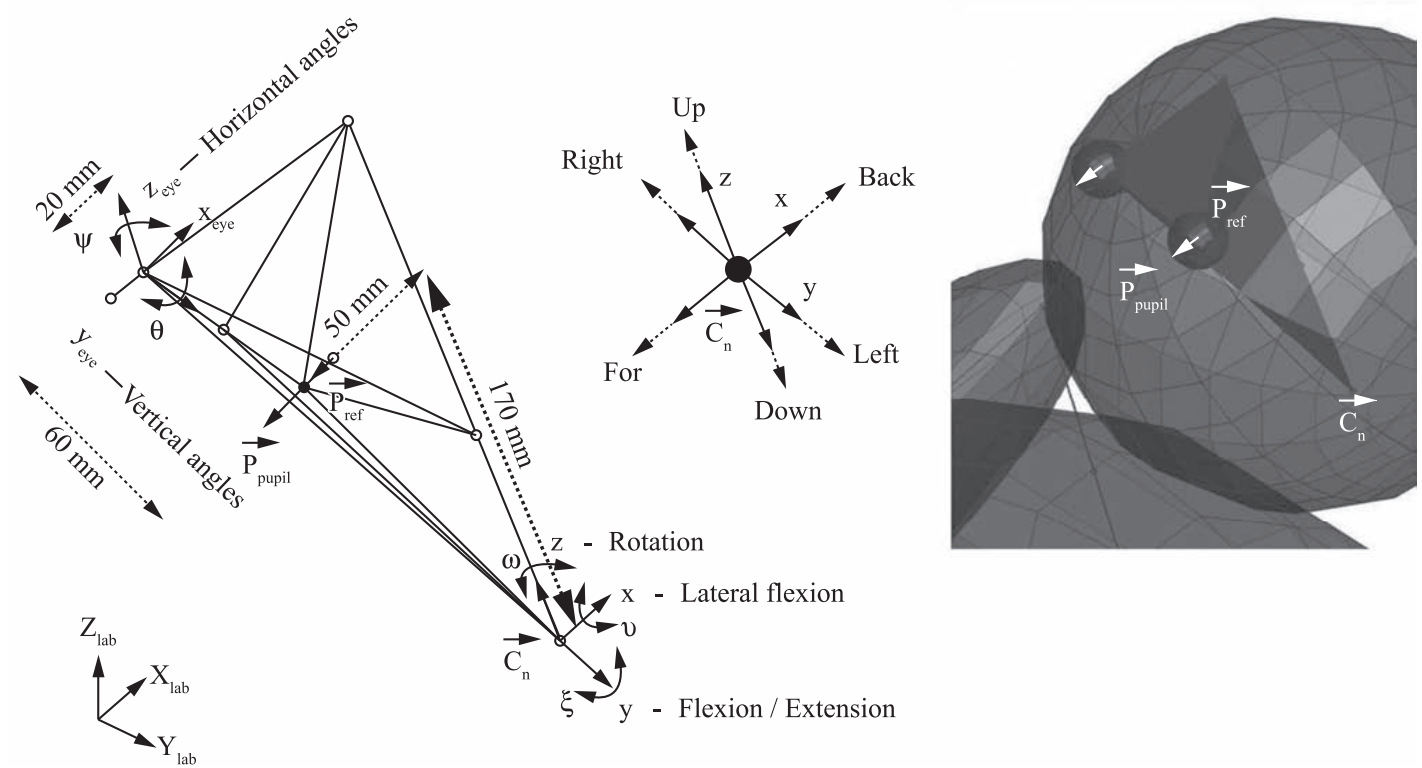

Figure 4. Position of the vectors to the movements of the eyes and head in the SimMechanics ${ }^{\mathrm{TM}}$ environment. Front view on the plane $\left(Y_{\text {lab }}\right.$ $\left.Z_{l a b}\right)$ and lateral view on the plane $\left(X_{l a b}, Z_{l a b}\right)$.

$$
\begin{aligned}
& {\left[\begin{array}{ccc}
\cos \omega & \sin \omega & 0 \\
-\sin \omega & \cos \omega & 0 \\
0 & 0 & 1
\end{array}\right] \times\left[\begin{array}{ccc}
R_{11} & R_{12} & R_{13} \\
R_{21} & R_{22} & R_{23} \\
R_{31} & R_{32} & R_{33}
\end{array}\right]=} \\
& {\left[\begin{array}{ccc}
\cos \xi & 0 & \sin \xi \\
0 & 1 & 0 \\
-\sin \xi & 0 & \cos \xi
\end{array}\right] \times\left[\begin{array}{ccc}
1 & 0 & 0 \\
0 & \cos \vartheta & -\sin \vartheta \\
0 & \sin \vartheta & \cos \vartheta
\end{array}\right]} \\
& R_{11} \cos \omega+R_{21} \sin \omega=\cos \xi \\
& R_{12} \cos \omega+R_{22} \sin \omega=\sin \xi \sin \vartheta \\
& R_{13} \cos \omega+R_{23} \sin \omega=\sin \xi \cos \vartheta \\
& -R_{11} \sin \omega+R_{21} \cos \omega=0 \\
& R_{33}=\cos \xi \cos \vartheta \\
& R_{32}=\cos \xi \sin \vartheta \\
& R_{31}=-\sin \xi \\
& -R_{13} \sin \omega+R_{22} \cos \omega=-\sin \vartheta
\end{aligned}
$$

From the Equation 18, the angle $\omega$ is calculated by: $\frac{\sin \omega}{\cos \omega}=\frac{-R_{21}}{-R_{11}} \Rightarrow \omega=\arctan \left(-R_{21},-R_{11}\right)$

From the Equations 15 and 21, the angle $\xi$ is defined as:

$\xi=\arctan \left(-R_{31}, R_{11} \cos \omega+R_{21} \sin \omega\right)$

From the Equations 19 and 21, the angle $\vartheta$ is given as:

$\vartheta=\arctan \left(R_{13} \sin \omega-R_{23} \cos \omega,-R_{12} \sin \omega+R_{22} \cos \omega\right)$

\section{Gaze positions}

Although the biomechanical model reconstructed in the SimMechanics ${ }^{\mathrm{TM}}$ environment can include the head and eyes, the gaze positions are still undetermined. The measurements of such positions begin with a development of an additional algorithm which defines an initial vector from the mechanical structure and represents the eye in the head demonstrated in the Figure 4 as:

$\vec{P}_{\text {initial }}(t)=\vec{P}_{\text {pupil }}(t)-\vec{P}_{\text {ref }}(t)$

The initial positions $\vec{P}_{\text {ref }}$ inside the head and $\vec{P}_{\text {pupil }}$ can be estimated using anthropometric cranio-orbital parameters (Evereklioglu et al., 2002; Farkas and Kolar, 1987; Farkas et al., 2005; Öztürk et al., 2006; Waitzman et al., 1992). The interpupillary distance is assumed to be $60 \mathrm{~mm}$, the diameter of the eyeball 
$20 \mathrm{~mm}$ and $\vec{P}_{\text {ref }}$ is assumed to be $170 \mathrm{~mm}$ above and $50 \mathrm{~mm}$ forward of the neck joint center $\vec{c}_{n}$.

The rotation matrix $\left[R_{e}\right]$ is determined by the horizontal and vertical rotations of the eyeball in relation to the head as:

$R_{e}=R_{\text {eye }}(\mathrm{y}, \theta) \times R_{\text {eye }}(z, \psi)$

where:

$$
\begin{aligned}
& R_{\text {eye }}(y, \theta)=\left[\begin{array}{ccc}
\cos \theta & 0 & \sin \theta \\
0 & 1 & 0 \\
-\sin \theta & 0 & \cos \theta
\end{array}\right] \\
& R_{\text {eye }}(z, \psi)=\left[\begin{array}{ccc}
\cos \psi & -\sin \psi & 0 \\
\sin \psi & \cos \psi & 0 \\
0 & 0 & 1
\end{array}\right]
\end{aligned}
$$

After the left site multiplication with the transpose of $R_{\text {eye }}(\mathrm{y}, \theta)$, is found:

$$
\begin{aligned}
& R_{\text {eye }}=(\mathrm{y}, \theta)^{T} \times R_{e}=R_{\text {eye }}(z, \psi) \\
& {\left[\begin{array}{ccc}
\cos \theta & 0 & -\sin \theta \\
0 & 1 & 0 \\
\sin \theta & 0 & \cos \theta
\end{array}\right] \times\left[\begin{array}{lll}
R_{11} & R_{12} & R_{13} \\
R_{21} & R_{22} & R_{23} \\
R_{31} & R_{32} & R_{33}
\end{array}\right]} \\
& =\left[\begin{array}{ccc}
\cos \psi & -\sin \psi & 0 \\
\sin \psi & \cos \psi & 0 \\
0 & 0 & 1
\end{array}\right]
\end{aligned}
$$

$R_{11} \cos \theta-R_{31} \sin \theta=\cos \psi$

$R_{12} \cos \theta-R_{32} \sin \theta=\sin \psi$

$R_{13} \cos \theta-R_{33} \sin \theta=0$

$R_{21}=\sin \psi$

$R_{22}=\cos \psi$

$R_{23}=0$

$R_{11} \sin \theta+R_{31} \cos \theta=0$

$R_{12} \sin \theta+R_{32} \cos \theta=0$

$R_{13} \sin \theta+R_{33} \cos \theta=1$

From the Equations 36 and 37, the angle $\psi$ is calculated by:

$$
\frac{\sin \psi}{\cos \psi}=\frac{R_{21}}{R_{22}} \quad \Rightarrow \quad \psi=\arctan \left(R_{21}, R_{22}\right)
$$

From the Equation 35, the angle $\theta$ is defined as:

$\frac{\sin \theta}{\cos \theta}=\frac{R_{13}}{R_{33}} \quad \Rightarrow \quad \theta=\arctan \left(R_{13}, R_{33}\right)$

The final orientation of the vector defined by the fovea and the center of the pupil can be determined using:

$\vec{P}_{\text {final }}(t)=R_{e} \times \vec{P}_{\text {initial }}(t)$

$\vec{P}_{\text {pupil }}(t)=\vec{P}_{\text {final }}(t)+\vec{P}_{\text {ref }}(t)$

The final orientation vector of the pupil (Equation 45) can be extended multiplying it by a scalar factor from the new positions of $\vec{P}_{r e f}$ moved by the head in space but also from the new positions of the pupil $\vec{P}_{\text {pupil }}$ due to the rotations of the eyeball inside of the head following:

$\vec{P}_{\text {line_of_sight }}(t)=\vec{P}_{\text {pupil }}(t) \cdot f$

The factor $f$ provides the increase of the final vector outside of the eyeball determining 3D points $\left(P_{\text {line_of_sight }} x(t), P_{\text {line_of_sight }} y(t), P_{\text {line_of_sight }} z(t)\right)$ which belongs to the right and left lines of sight. The Euclidean distance between these points is minimal in space when the reflective marker placed at end effector of the robot is focused in motion by the eyes of the subject (Equation 47). In this situation, $40 \leq f \leq 60$ can be observed. With the minimal Euclidean distance during unconstrained movements of the head and eyes, two points of interest with $3 \mathrm{D}$ coordinates are found, one in the right line of sight $\left(P_{\text {right }} x(t), P_{\text {right }} y(t), P_{\text {right }}\right.$ $z(t))$ and the other in the left line of sight $\left(P_{\text {left }} x(t)\right.$, $\left.P_{\text {left }} y(t), P_{\text {left }} z(t)\right)$. Non-linear regression techniques were not applied.

$D(t)=\sqrt{\begin{array}{l}\left(P_{\text {righ }} x(t)-P_{\text {lef }} x(t)\right)^{2}+\left(P_{\text {righ }} y(t)-P_{\text {lef }} y(t)\right)^{2} \\ +\left(P_{\text {right }} z(t)-P_{\text {leff }} z(t)\right)^{2}\end{array}} \Rightarrow \min$

The gaze $\left(X_{\text {gaze }}(t), Y_{\text {gaze }}(t), Z_{\text {gaze }}(t)\right)$ is the midpoint between these two points of interest and its orientation vector in relation to the lab coordinate system is given as:

$\vec{P}_{\text {gaze }}=\left(\begin{array}{l}\frac{P_{\text {right }} x+P_{\text {left }} x}{2} \\ \frac{P_{\text {right }} y+P_{\text {left }} y}{2} \\ \frac{P_{\text {right }} z+P_{\text {left }} z}{2}\end{array}\right)=\left(\begin{array}{c}X_{\text {gaze }} \\ Y_{\text {gaze }} \\ Z_{\text {gaze }}\end{array}\right)$ 


\section{Evaluation of the eye-finger movements}

A ten camera Vicon motion analysis system was used to record the movements of the upper extremities. The calibration of the system defines the capture volume, relative positions and orientation of the cameras. There are two types of calibration: static and dynamic. Static calibration is used to set the origin and direction of the axes in the lab and the dynamic calibration is used to calculate the relative positions and orientation of the cameras. The act of this calibration involves motions throughout the capture volume waving the wand so that it passes through as much of the capture volume as possible allowing each camera to record the wand in several orientations. Vicon takes two dimensional data from each camera, combining it with calibration data to reconstruct the equivalent digital motion in three dimensions providing visualization in a virtual environment.

The angles of the eyes in horizontal and vertical directions were measured using an eye-tracker ELMAR 2020. It uses adaptive real-time image processing techniques to obtain accurate rotations of the eyeball. Each eye is illuminated by three infrared light emitting diodes (LEDs) that are mounted on an eye glasses frame. Images of the illuminated eyes are captured by video cameras inside the glasses using a pre-processor unit. The analysis is completed in the main processor unit and the estimated eye positions and pupil sizes are available in either analogue or digital forms. The subjects' eyes with superimposed tracking markers or squares around the corneal reflections and cross at the middle of the pupil are shown continuously on a video monitor. This device includes a built-in start and calibration procedures. The start procedure allows the eye tracker's software and hardware to optimize their performance with different subjects and under different test conditions. The calibration procedure permits the transformation of pupil and cornea motions in camera pixels to the eye positions in degrees. There are four modes of calibration: normal, center, right eye and left eye but for our experiments only the first one was used. In the normal calibration procedure both eyes are calibrated simultaneously and it requires the presentation of three to seven points along the horizontal axis and three to seven points along the vertical axis on a vertical tablet placed in front of the subjects. During this procedure, head motions are considered stable and the movements of the pupil and the corneal reflections are correlated with the known positions of the calibration points. At the end of the calibration routine the eye position data in degrees is scaled according to the movements of the calibrating target. If the subject blinks during the recording of data, the points can be re-tried. During the calibration procedure the operator should watch the video monitor to make sure that for most of the calibration points the cross in the middle of the pupil and the squares around the corneas are present. The movements of the eyes in relation to the head are electronically synchronized with the Vicon motion analysis system while the subjects follow a robot with free movements of the head defined by three reflective markers placed on the glass of the eye-tracker.

The lightweight robot LBR-IV developed by German Aerospace Center (DLR), presents redundant kinematics and seven degrees of freedom which allow more complexity in the execution of the movements. Sensors can still evaluate the torque in each joint providing a new implementation in the control laws, as the compensation of the gravity and the reaction velocity when the robot is submitted to the effects of external forces. The robot was previously programmed to execute trajectories using a reflective marker placed at the end effector as a visual reference in motion (Popovic et al., 2009). The procedure was tested in two experiments. In the first one, a group of 14 healthy subjects between 20 and 30 years old with no history of neuromuscular and ocular disease were chosen and the previous knowledge of the trajectory of the robot was not omitted. The subjects focused with the eyes on the marker of the robot and followed its trajectory with another reflective maker placed at the finger. The movements provided three ellipsoidal, cyclical and reproducible trajectories with constant velocities of 25,80 and $100 \mathrm{~mm} / \mathrm{s}$ and amplitudes of 117.63 , 521.64 and $713.28 \mathrm{~mm}$ in the $x, y$ and $z$ directions respectively. After that, 5 new healthy subjects also between 20 and 30 years old with no history of neuromuscular and ocular disease were chosen to execute another trajectory with different velocities in the $x$ direction from 10 to $250 \mathrm{~mm} / \mathrm{s}$, in the $y$ direction from 15 to $300 \mathrm{~mm} / \mathrm{s}$ and in the $z$ direction from 10 to $800 \mathrm{~mm} / \mathrm{s}$, respectively. The previous knowledge of this new trajectory was omitted to the second experiment and in both situations the point of gaze between the lines of sight was also calculated.

The calibration of the cameras defined a global coordinate system $\left(X_{l a b}, Y_{l a b}, Z_{l a b}\right)$ in the lab where the reflective markers on the subjects and at the end effector of the robot were captured at the same time. The origin of the global coordinate system is located in front of the robot and the $x, y$ and $z$ axes correspond to the depth, width and height dimensions, respectively (Figure 5). The robot and the subjects were always placed in the same position in relation to the global coordinate system providing to evaluate the movements to the same robot trajectory between the subjects. 


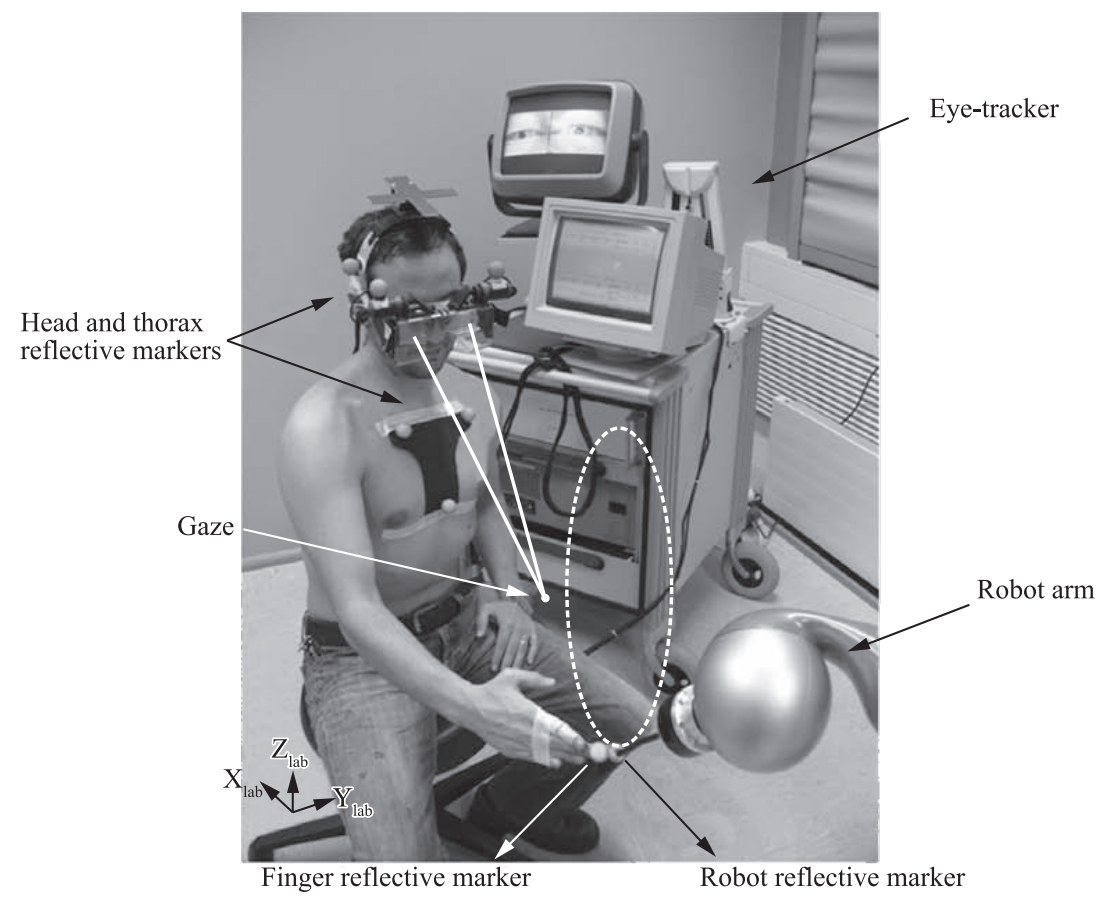

Figure 5. 3D Tracking. Subject following a trajectory of the robot LBR-IV using the glass of the eye-tracker. Front view on the plane $\left(Y_{l a b}\right.$, $\left.Z_{l a b}\right)$ and lateral view on the plane $\left(X_{l a b}, Z_{l a b}\right)$.

\section{Results}

The results of the head movements of 14 subjects are shown in the Figure 6. The head moves in terms of flexion/extension when the subject looks down or up, rotation when he looks to the right or left and lateral flexion when he nods the head. The lateral flexion is small because this movement is not almost necessary when the subject follows the simple robot path. At the same time, the movements of the neck

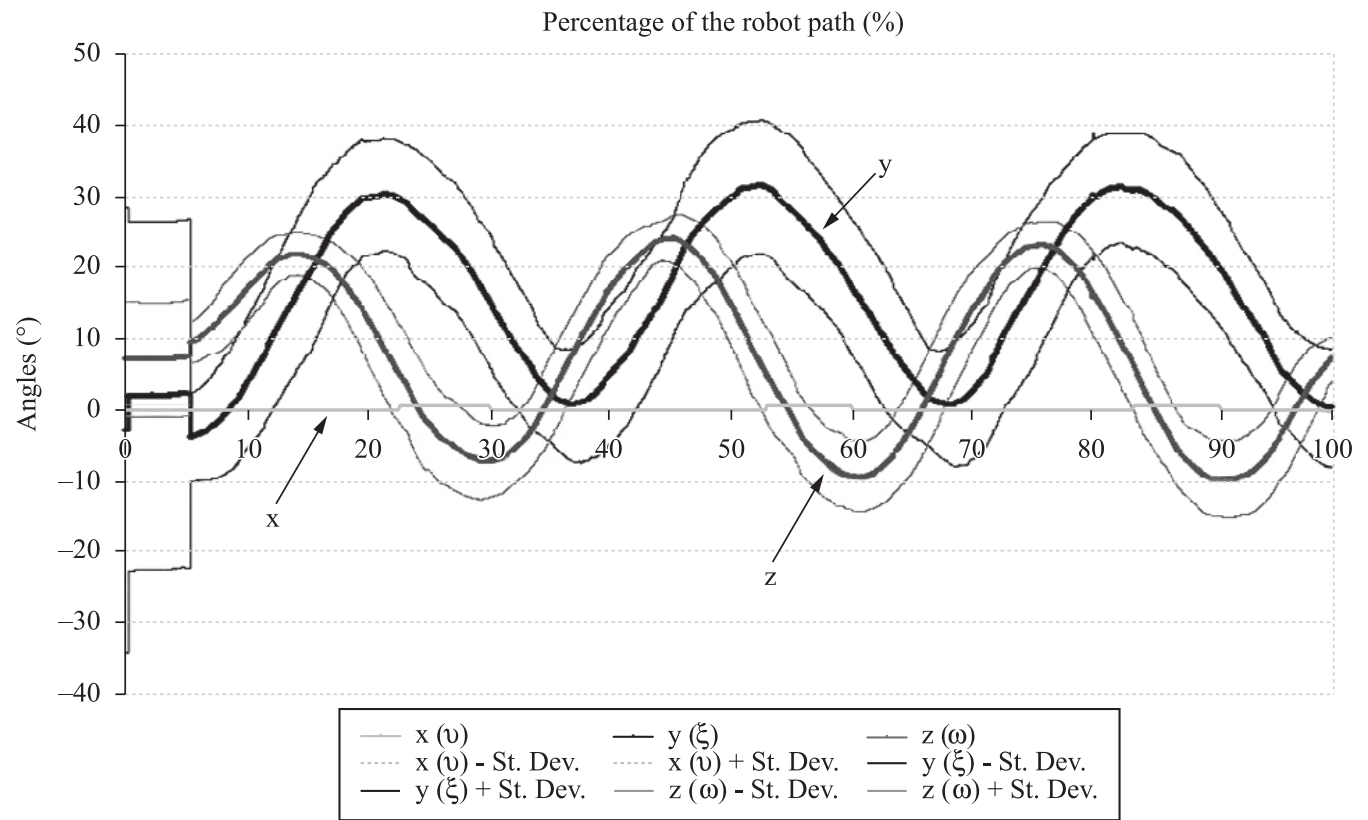

Figure 6. Rotations of the head to the trajectory of the robot with constant velocity. 


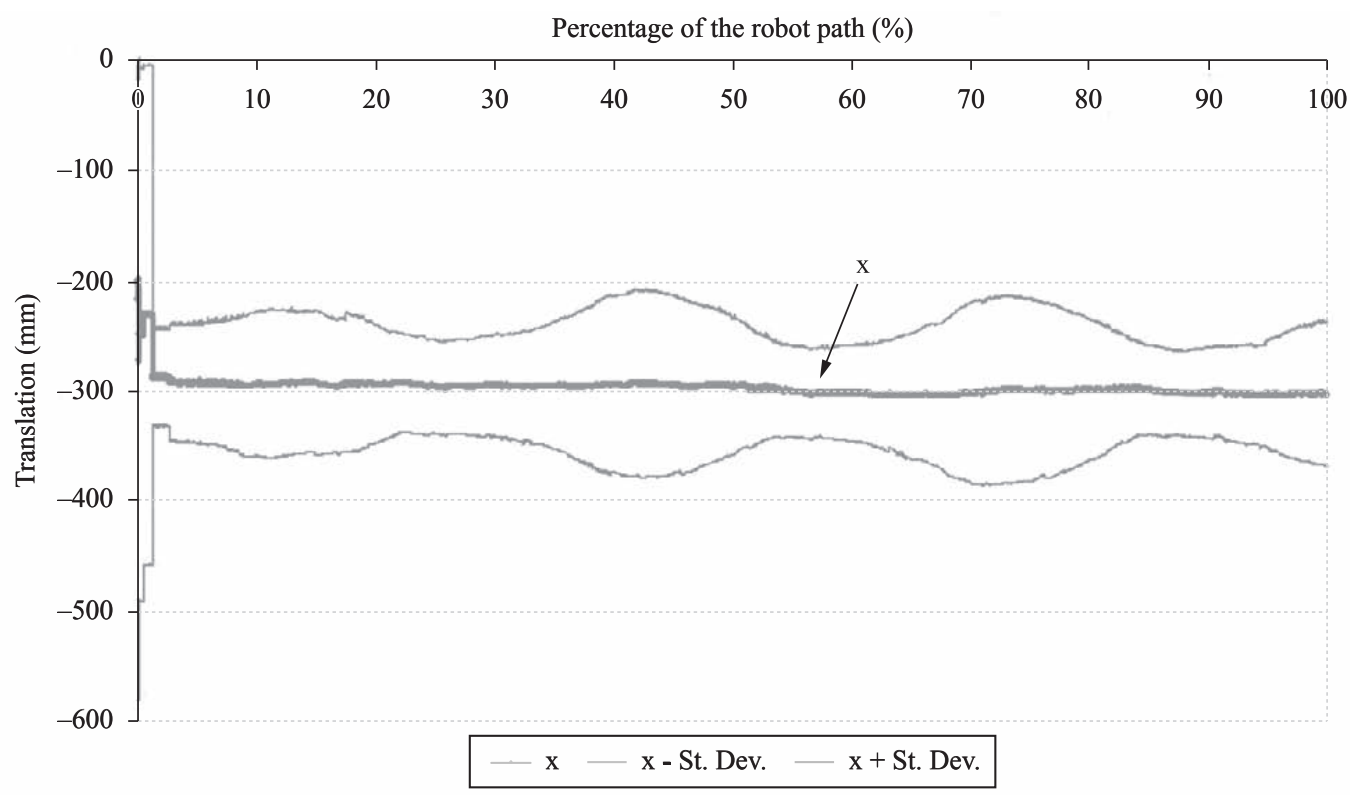

Figure 7. Translation of the neck joint center $\vec{c}_{n}$ going backwards or forwards in the $x$ direction to the trajectory of the robot with constant velocity.

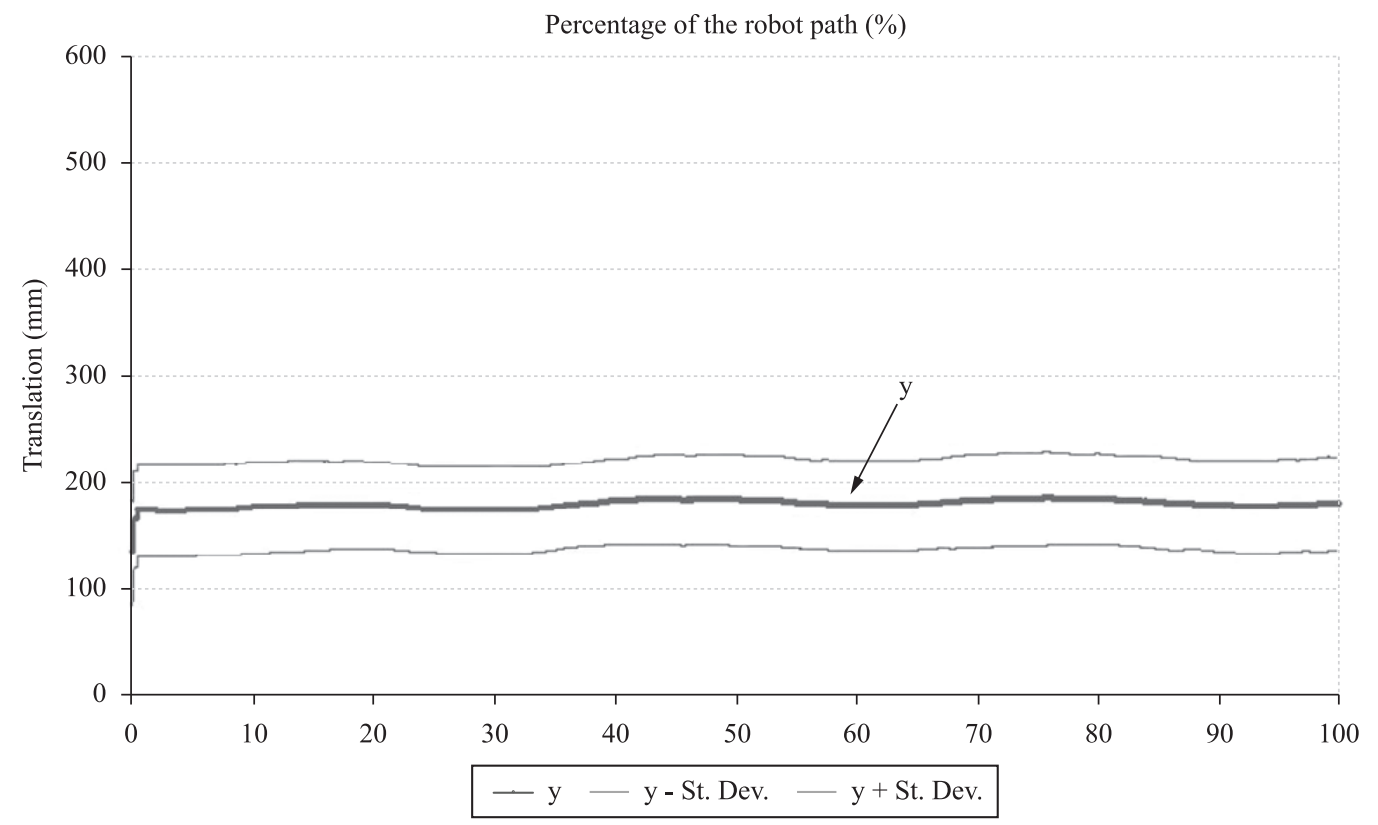

Figure 8. Translation of the neck joint center $\vec{c}_{n}$ going to the left or right in the $y$ direction to the trajectory of the robot with constant velocity.

joint center $\vec{c}_{n}$ are presented in the Figures 7-9. The position of $\vec{c}_{n}$ remains constant to the left and right in the $y$ axis and up and down in the $z$ axis, but it presents small movements forwards and backwards in the $x$ axis when the subject tries to focus on the reflective marker placed at end effector of the robot. The movements presents oscillations around the mean movement of $60.52,42.38,38.67 \mathrm{~mm}$, in the $x, y$ and $z$ axes, respectively.

At the same time, the eye-tracker measures the horizontal and vertical angles for each eye. The measurements are shown in the Figures 10 and 11.

Figures 12-14 show the movements of the gaze and finger when the subjects followed a simple path 


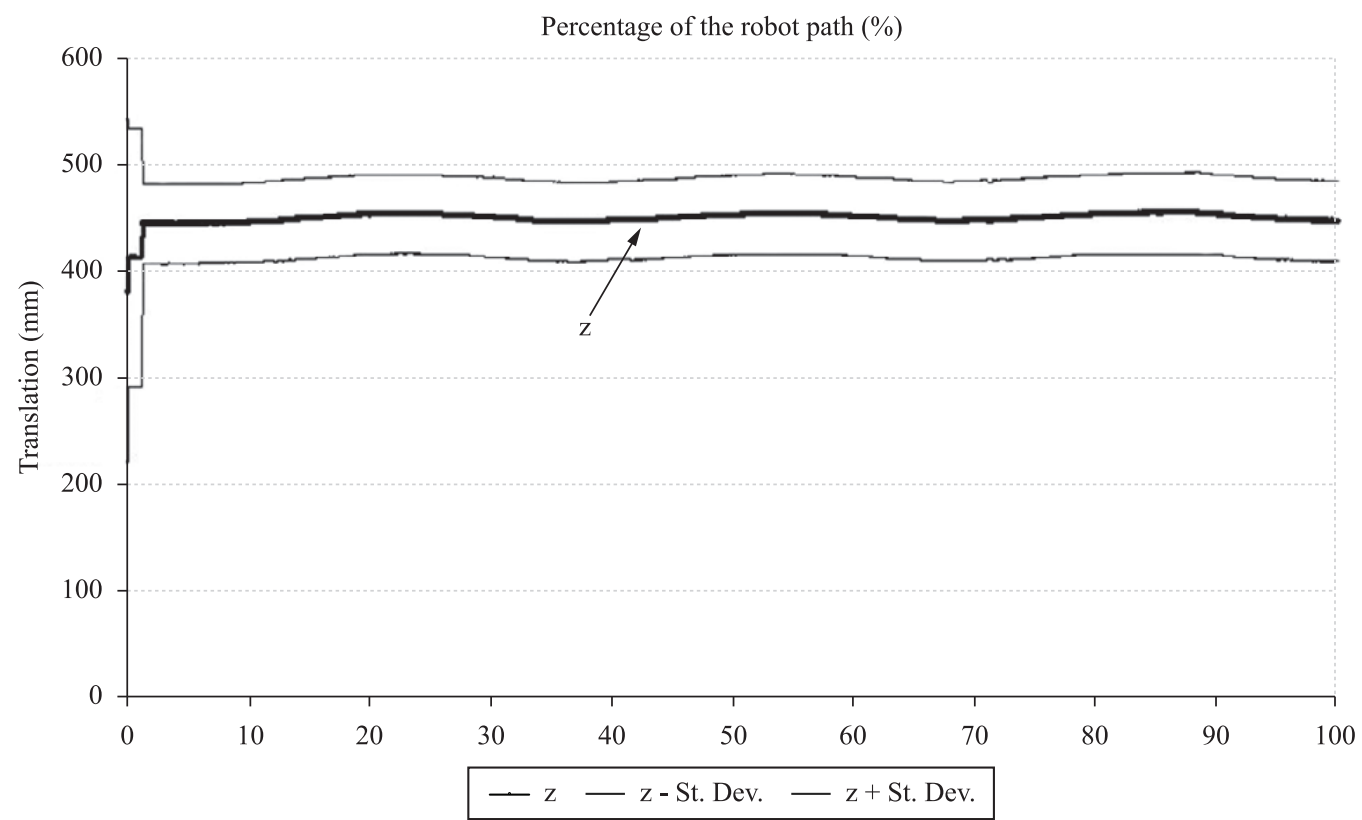

Figure 9. Translation of the neck joint center $\vec{c}_{n}$ going up or down in the $z$ direction to the trajectory of the robot with constant velocity.

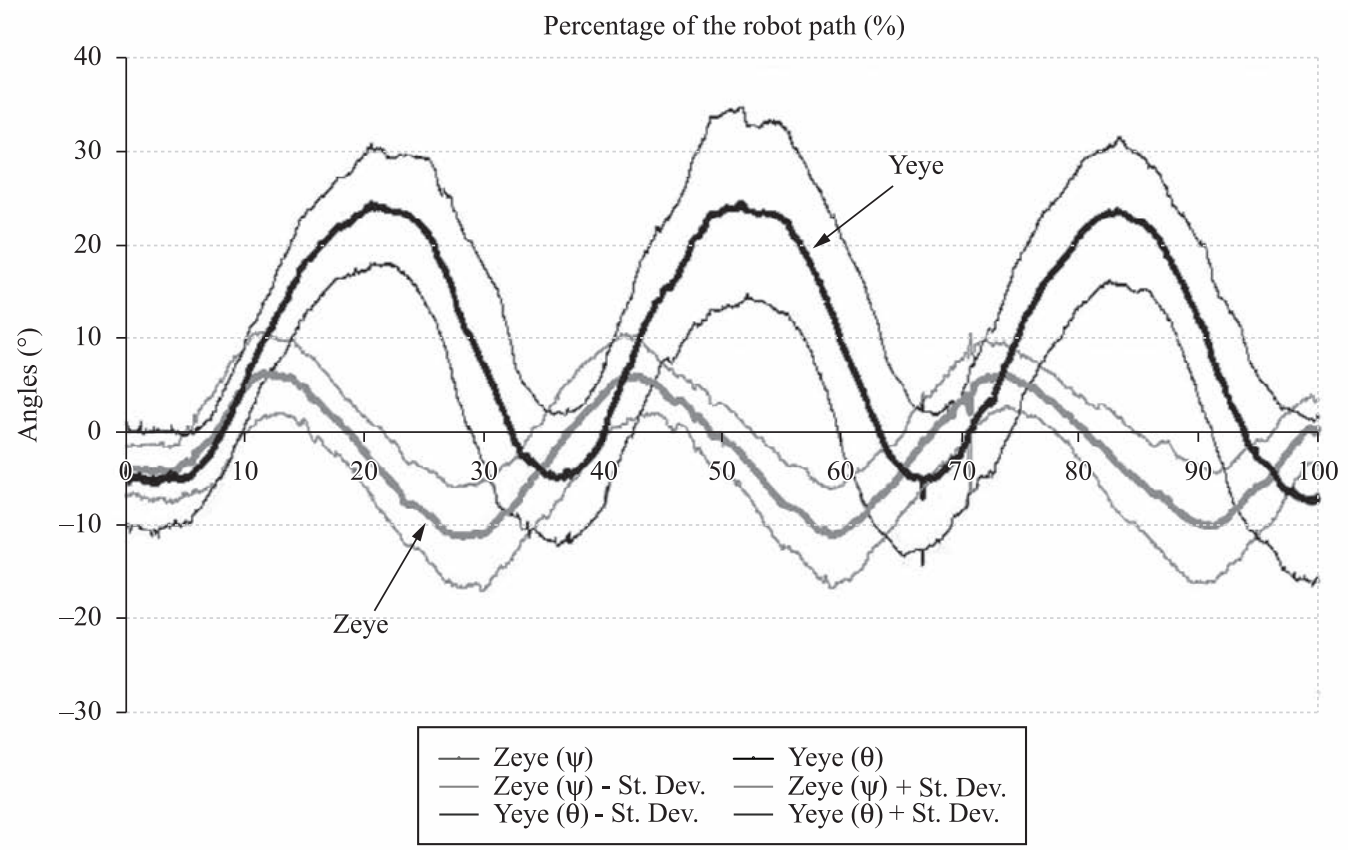

Figure 10. Rotations of the right eye to the trajectory of the robot with constant velocity.

executed by the robot with constant velocity. In the $x$ direction, the amplitude of the robot's trajectory is smaller and therefore the main movements of the robot happen in the $(y, z)$ plane. The gaze trajectory in the $x$ direction has larger amplitude when compared with the finger and the robot trajectories because the subjects tried to control the perception of depth focusing on the robot in motion. In the $y$ and $z$ directions the trajectories seem to be almost synchronized mainly, due to the compensations of the head, eye and finger movements.

For validation of the reproducibility between the movements of the gaze, finger and robot, the Pearson moment correlation coefficients of the 14 subjects were calculated. The trajectories between the gaze-finger, 


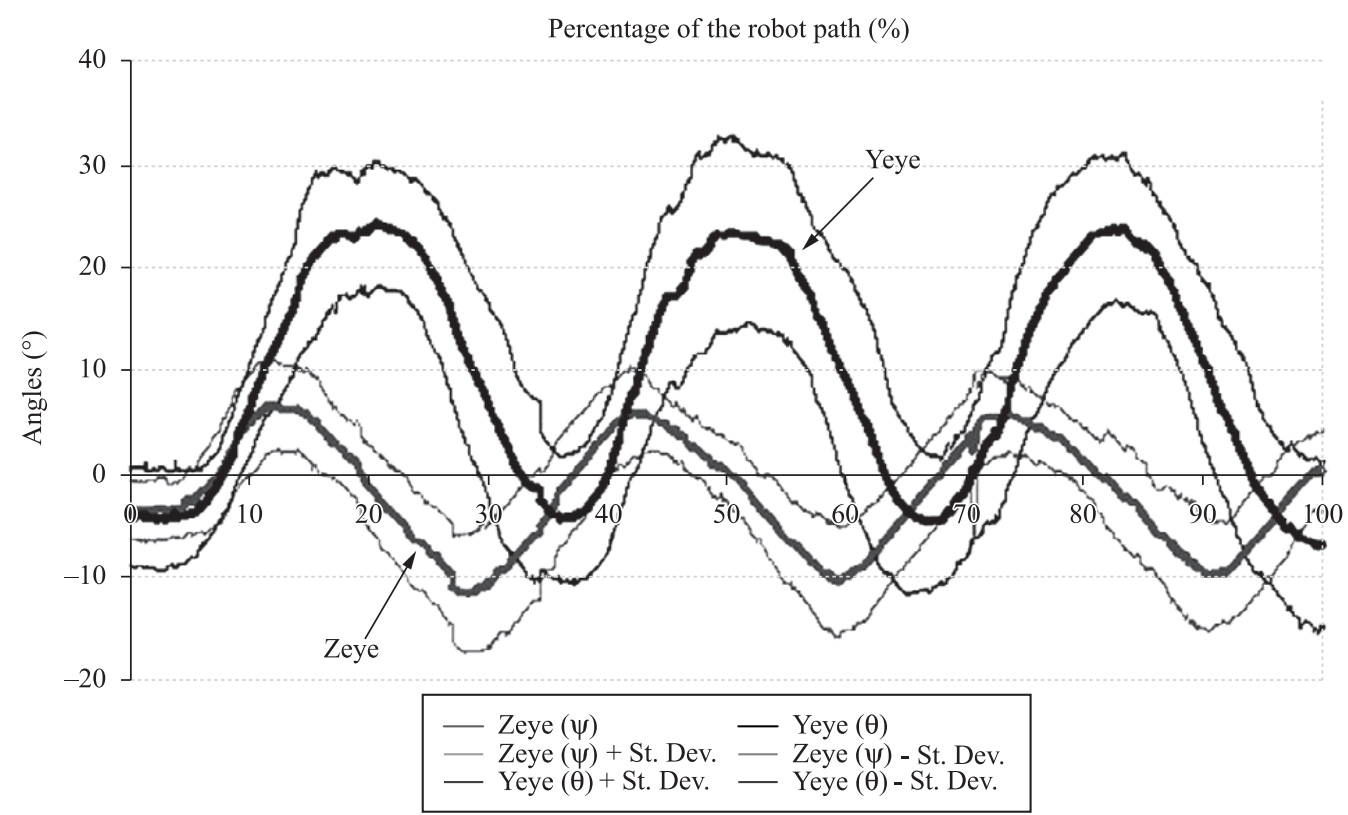

Figure 11. Rotations of the left eye to the trajectory of the robot with constant velocity.

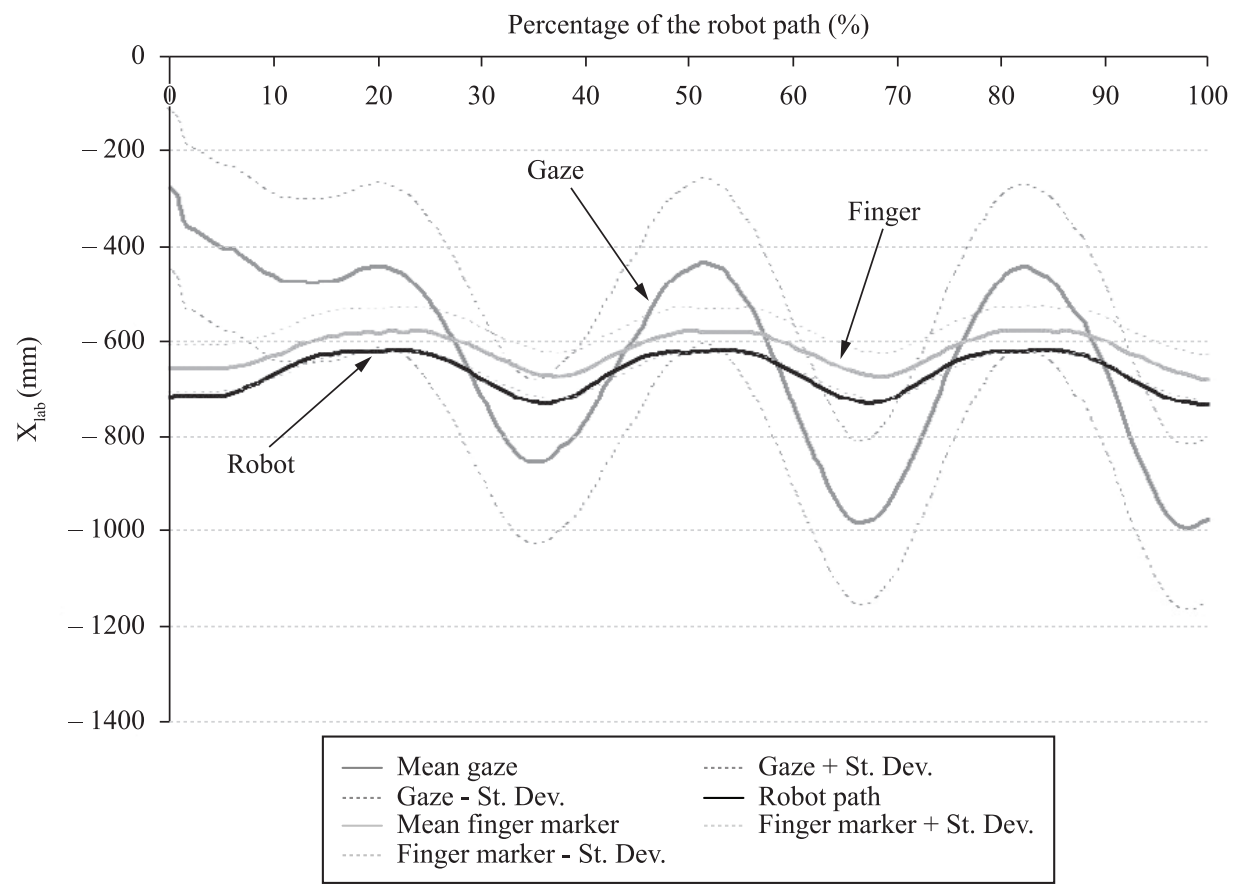

Figure 12. $X$ movements of the gaze, finger and robot in space to the simple robot trajectory with constant velocity.

the gaze-robot and the finger-robot were compared. Table 1 shows that the coefficients to the $y(0.93-0.99)$ and $z$ (0.89-0.99) directions were significantly higher than the $x$ direction. The ranges of the standard deviations of the mean correlation coefficient were 0.0003-0.02 and 0.001-0.05, respectively. In the $x$ direction the mean Pearson correlation coefficients presented results between $0.56-0.96$ with standard deviations between $0.05-0.23$.

To the second experiment, the subjects tried to follow another trajectory with different velocities using the eyes and finger (Figures 15-17). Although 


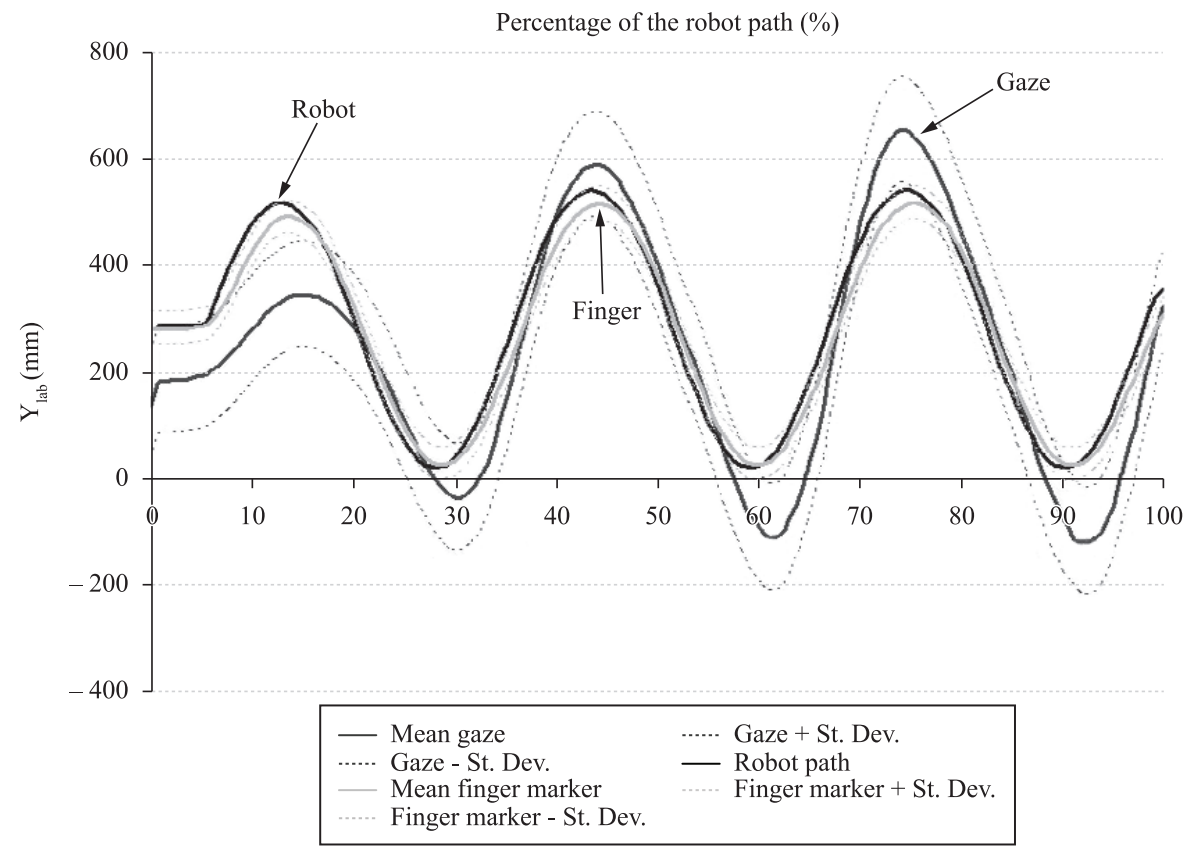

Figure 13. $Y$ movements of the gaze, finger and robot in space to the simple robot trajectory with constant velocity.

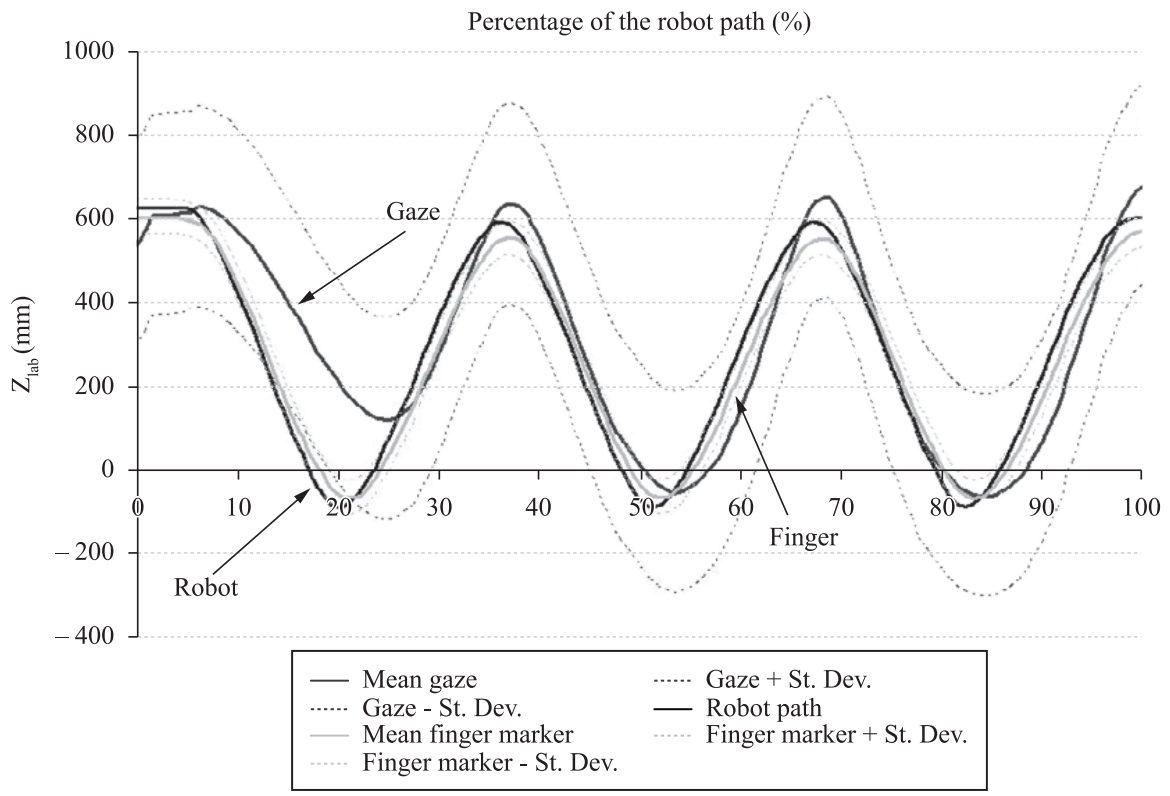

Figure 14. $Z$ movements of the gaze, finger and robot in space to the simple robot trajectory with constant velocity.

Table 1. First Experiment: mean Pearson correlation coefficients with standard deviations of 14 subjects to the robot trajectory with constant velocity.

\begin{tabular}{lcll}
\hline Trajectories & $x$ & \multicolumn{1}{c}{$y$} & \multicolumn{1}{c}{$z$} \\
\hline Gaze-finger & $0.56 \pm 0.23$ & $0.93 \pm 0.02$ & $0.89 \pm 0.05$ \\
Gaze-robot & $0.56 \pm 0.21$ & $0.93 \pm 0.02$ & $0.90 \pm 0.05$ \\
Finger-robot & $0.96 \pm 0.05$ & $0.99 \pm 0.0003$ & $0.99 \pm 0.001$ \\
\hline
\end{tabular}

the movements of the robot seem to be more complex when compared with the first experiment, the finger follows the robot movements in the $x, y$ and $z$ directions but the amplitude of the gaze movements is smaller mainly in the $z$ direction.

The Pearson correlation coefficients of 5 subjects between the gaze-finger, the gaze-robot and the 


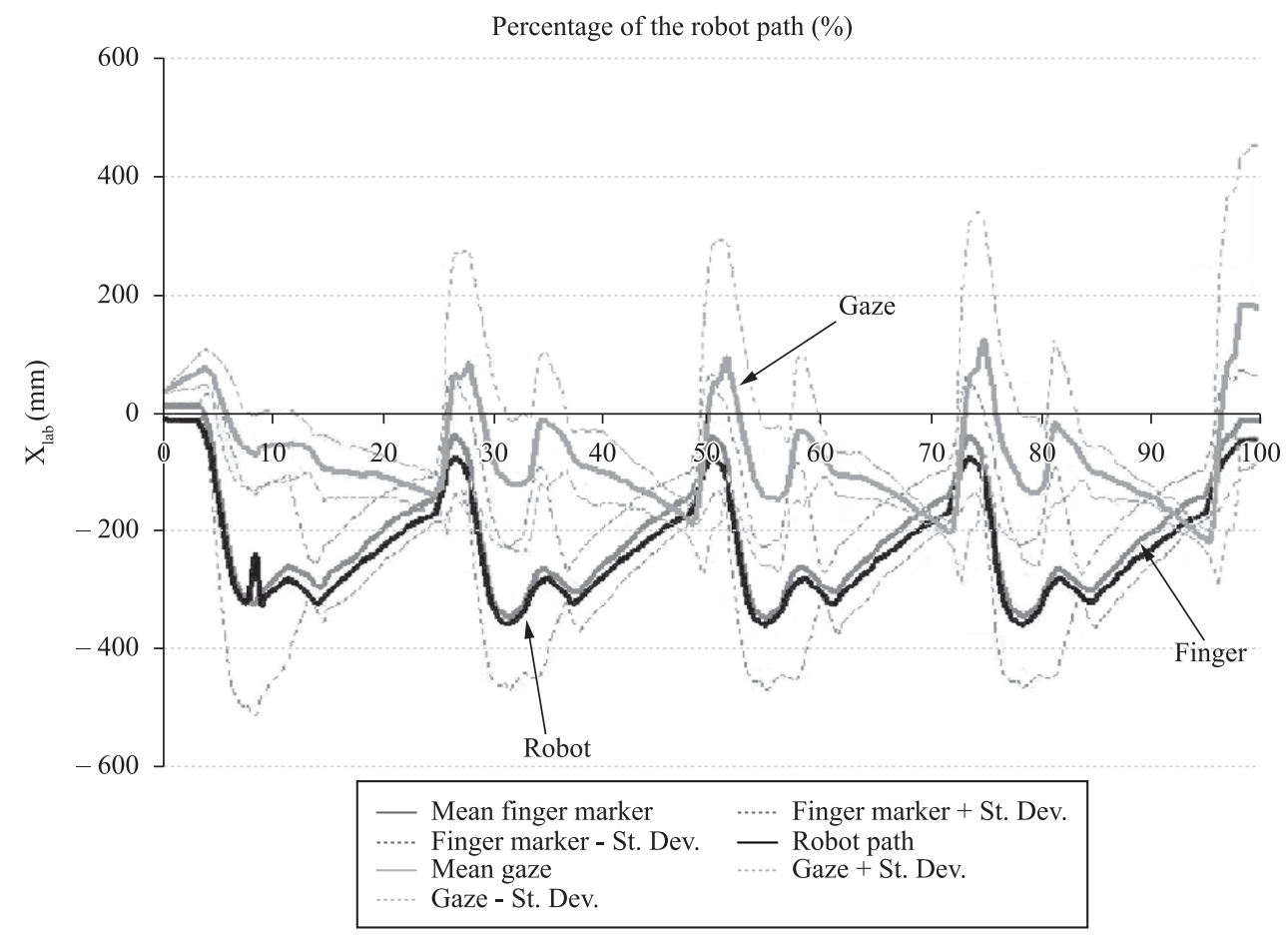

Figure 15. $X$ movements of the gaze, finger and robot in space to the complex robot trajectory with different velocities.

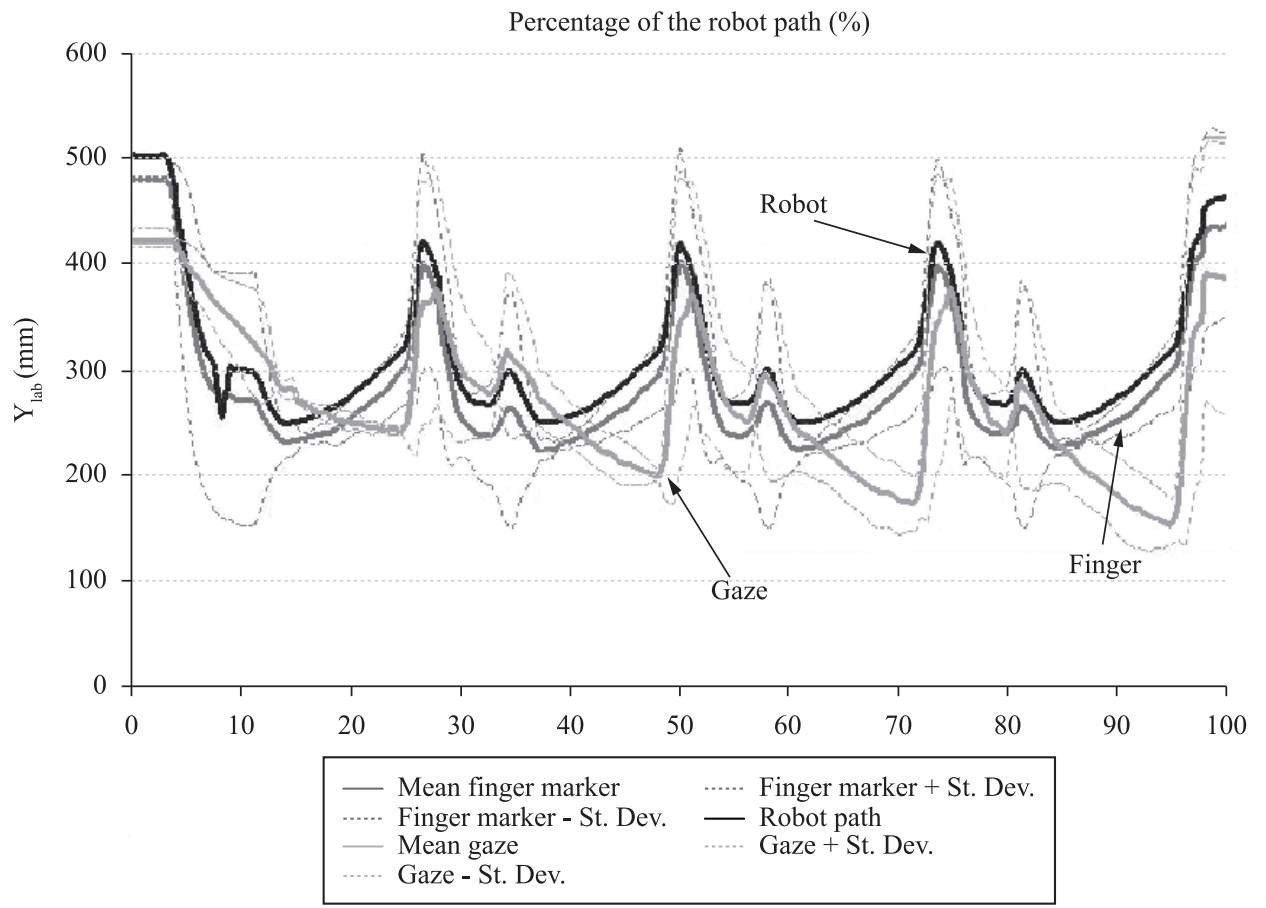

Figure 16. $Y$ movements of the gaze, finger and robot in space to the complex robot trajectory with different velocities. 


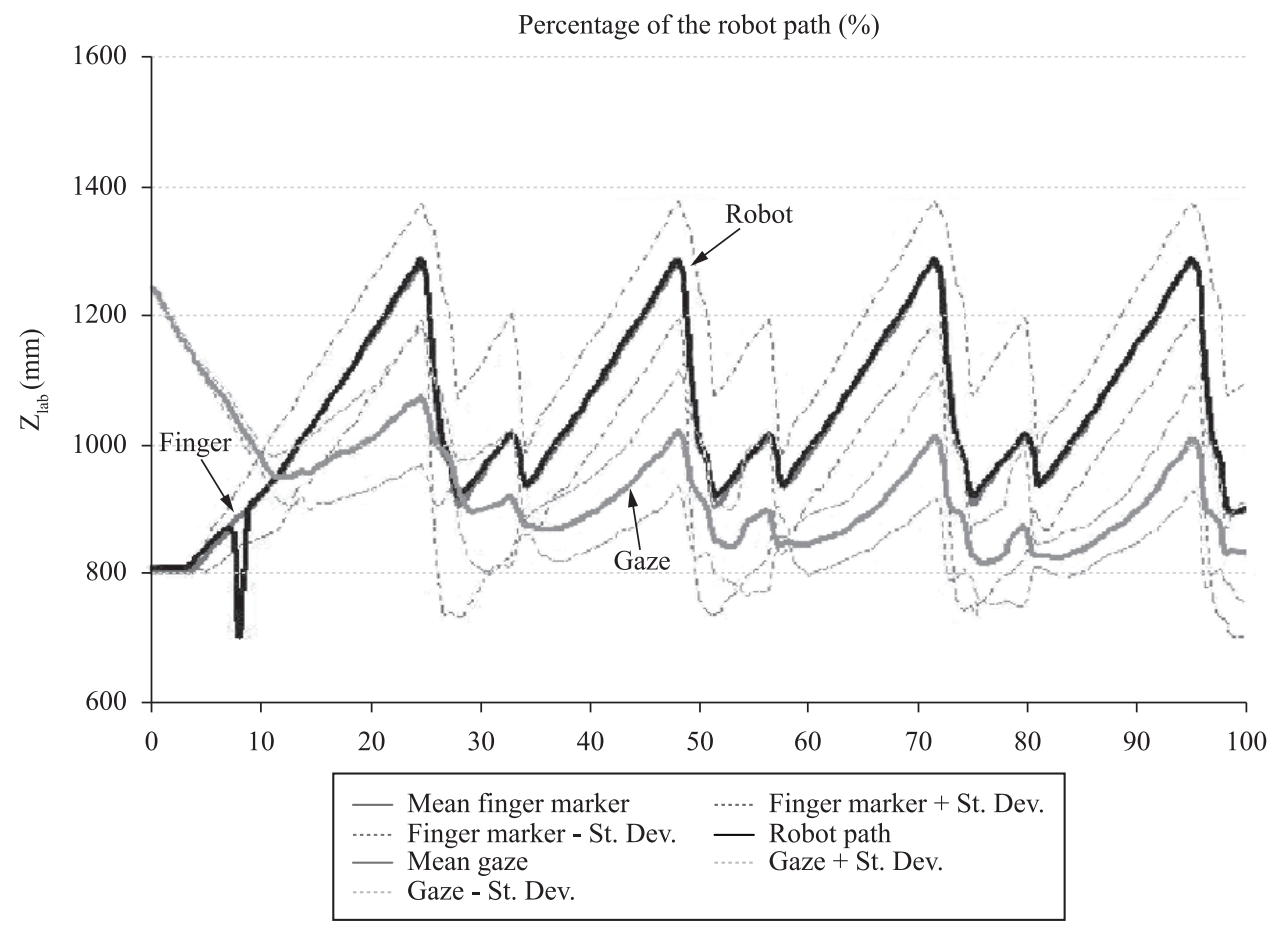

Figure 17. $Z$ movements of the gaze, finger and robot in space to the complex robot trajectory with different velocities.

Table 2. Second Experiment: mean Pearson correlation coefficients with standard deviations of 5 subjects to the robot trajectory with different velocities.

\begin{tabular}{lccc}
\hline \multicolumn{1}{c}{ Trajectories } & $x$ & $y$ & $z$ \\
\hline Gaze-finger & $0.43 \pm 0.04$ & $0.66 \pm 0.05$ & $0.33 \pm 0.05$ \\
Gaze-robot & $0.43 \pm 0.04$ & $0.67 \pm 0.05$ & $0.31 \pm 0.06$ \\
Finger-robot & $0.98 \pm 0.02$ & $0.99 \pm 0.01$ & $0.98 \pm 0.03$ \\
\hline
\end{tabular}

finger-robot trajectories are showed in the Table 2. The coefficients to the finger-robot trajectory were significantly higher to the $x(0.98 \pm 0.02), y$ $(0.99 \pm 0.01)$ and $z(0.98 \pm 0.03)$ directions. The gaze-finger trajectory presented coefficients between 0.33-0.66 with standard deviations between 0.04-0.05 and the gaze-robot trajectory presented coefficients between $0.31-0.67$ with standard deviations between 0.04-0.06.

\section{Discussion}

The movements between the gaze, finger and robot are based on a SimMechanics ${ }^{\mathrm{TM}}$ environment where an eye-head biomechanical model was developed regarding mathematical considerations proposed by Schmidt et al. (1999) and Williams et al. (2006) to the analysis of the upper extremity movements. The eyes were placed inside the head considering references of anthropometric cranio-orbital measurements.
Although these measurements seem to be consistent with literature or with small deviations between subjects, the eyes are not considered rigid bodies in natural conditions but in this case they presented satisfactory rotational movements with the angles previously measured with the eye-tracker.

In terms of the first experiment, the deviations were evaluated analyzing the set of recordings of 14 subjects and no previously estimated measurement uncertainty was considered. Furthermore, the mean Pearson coefficients showed higher correlations with small deviations between the gaze, finger and robot trajectories mainly in the $y$ and $z$ directions with constant velocity (Table 1). This result can also be observed in $x$ axis but only to the finger-robot trajectory. The gaze-finger and gaze-robot trajectories presented lower correlations with higher deviations because the gaze does not perfectly follow the robot and finger trajectories in depth dimension due to the stereopsis. It is an ability to make fine depth discriminations from parallax provided by the two different positions of the eyes on the head. Parallax is an apparent displacement or difference in the apparent position of the reflective marker at end effector of the robot viewed along two different lines of sight and it is measured by the angles of inclination of the eyes.

The subjects of the second experiment presented higher Pearson coefficients to the robot-finger trajectory 
in the $x, y$ and $z$ directions, respectively, and lower to the gaze-finger and gaze-robot trajectories (Table 2) because the visual feedback of the reflective marker placed at the end effector of the robot in motion was less used to plan the movements in relation to the new trajectory of the robot. In this situation, the subjects were not advised about the alteration of velocities during the experiment and their movements were visually accompanied by the researchers in the lab. During the execution of the movements, the subjects did not focus exactly on the reflective marker of the robot in motion to execute their movements. It happened because they did not elevate completely the head while they followed the trajectory of the robot with the finger. It can suggest that movements between the eyes, head and arm could be already generating somatosensory information in the nervous system. In general, somatosensory information could be described as proprioception provided by sensory receptors in muscles, tendon, joints and skin and are also involved in the direction and learning of new movements (Cordo et al., 1994). Such information could be interacting themselves, reducing the importance of the focal direction because the amplitude of the gaze movements are smaller than the amplitude of the finger and robot movements (Figure 17) mainly in the $z$ direction. The subjects could be learning the movements of the new trajectory although with different velocities. Such fact allows that the subjects follow the reflective marker of the robot with the finger.

The method can quantitatively measure the positions between the finger and gaze in relation to a visual target attached to a robot arm in motion. The methodology could be used on clinical applications to observe whether patients have motor cognitive diseases as e.g. Balint's syndrome, Parkinson's disease, optic apraxia and ataxia, respectively.

\section{Acknowledgements}

The authors gratefully acknowledge the financial support provided by CAPES-Brazil, DAAD-Germany and AME/RPE - Helmholtz Institut.

\section{References}

Bernier PM, Chua R, Franks IM. Is proprioception calibrated during visually guided movements? Experimental Brain Research. 2005; 167(2):292-6. PMid:16044301. http:// dx.doi.org/10.1007/s00221-005-0063-5

Cordo P, Carlton L, Bevan L, Carlton M, Kerr GK. Proprioceptive coordination of movement sequences: role of velocity and position information. Journal of Neurophysiology. 1994; 71(5):1848-61.
Evereklioglu C, Doganay S, Er H, Gunduz A, Tercan M, Balat A, Cumurcu T. Craniofacial anthropometry in a Turkish population. Cleft Palate-Craniofacial Journal. 2002; 39(2):208-18. http://dx.doi.org/10.1597/15451569(2002)039\%3C0208:CAIATP\%3E2.0.CO;2

Farkas LG, Katic MJ, Forrest CR, Alt KW, Bagic I, Baltadjiev G, Cunha E, Cvicelova M, Davies S, Erasmus I, Gillett-Netting R, Hajnis K, Kemkes-Grottenthaler A, Khomyakova I, Kumi A, Kgamphe JS, Kayo-daigo N, Le T, Malinowski A, Negasheva M, Manolis S, Ogeturk M, Parvizrad R, Rosing F, Sahu P, Sforza C, Sivkov S, Sultanova N, Tomazo-Ravnik T, Toth G, Uzun A, Yahia E. International anthropometric study of facial morphology in various ethnic groups/races. The Journal of Craniofacial Surgery. 2005; 16(4):615-46. PMid:16077306. http://dx.doi. org/10.1097/01.scs.0000171847.58031.9e

Farkas LG, Kolar JC. Anthropometric guidelines in cranioorbital surgery. Clinics in Plastic Surgery. 1987; 14(1):1-16.

Gowen E, Miall RC. Eye-hand interactions in tracing and drawing tasks. Human Movement Science. 2006; 25:56885. PMid:16891021. http://dx.doi.org/10.1016/j. humov.2006.06.005

Horstmann A, Hoffmann KP. Target selection in eyehand coordination: Do we reach to where we look or do we look to where we reach? Experimental Brain Research. 2005; 167(2):187-95. PMid:16044304. http:// dx.doi.org/10.1007/s00221-005-0038-6

Lateiner JE, Sainburg RL. Differential contributions of vision and proprioception to movement accuracy. Experimental Brain Research. 2003; 151(4):446-54. PMid:12830345. http://dx.doi.org/10.1007/s00221-003-1503-8

Öztürk F, Yavas G, Inan UU. Normal periocular anthropometric measurements in the Turkish population. Ophthalmic Epidemiology. 2006; 13(2):145-9. PMid:16581619. http:// dx.doi.org/10.1080/09286580500507220

Pelz J, Hayhoe M, Loeber R. The coordination of eye, head, and hand movements in a natural task. Experimental Brain Research. 2001; 139(3):266-77. http://dx.doi.org/10.1007/ s002210100745

Popovic N, Williams S, Schmitz-Rode T, Rau G, Disselhorst-Klug C. Robot-based methodology for a kinematic and kinetic analysis of unconstrained, but reproducible upper extremity movement. Journal of Biomechanics. 2009; 42(10):1570-3. PMid:19442979. http://dx.doi.org/10.1016/j.jbiomech.2009.03.042

Sarlegna F, Blouin J, Bresciani JP, Bourdin C, Vercher JL, Gauthier GM. Target and hand position information in the online control of goal-directed arm movements. Experimental Brain Research. 2003; 151(4):524-35. PMid:12830346. http://dx.doi.org/10.1007/s00221-003-1504-7

Schmidt R, Disselhorst-Klug C, Silny J, Rau G. A markerbased measurement procedure for unconstrained wrist and elbow motions. Journal of Biomechanics. 1999; 32(6):61521. http://dx.doi.org/10.1016/S0021-9290(99)00036-6

Vercher JL, Magenes G, Prablanc C, Gauthier GM. Eyehead-hand coordination in pointing at visual targets: spatial and temporal analysis. Experimental Brain 
Research. 1994; 99(3):507-23. http://dx.doi.org/10.1007/ BF00228987

Vercher JL, Sarès F, Blouin J, Bourdin C, Gauthier GM. Role of sensory information in updating internal models of the effector during arm tracking. Progress in Brain Research. 2003; 142:203-22. http://dx.doi.org/10.1016/ S0079-6123(03)42015-3

Waitzman AA, Posnick JC, Armstrong DC, Pron GE. Craniofacial skeletal measurements based on computed tomography: Part II. Normal values and growth trends Cleft Palate-Craniofacial Journal. 1992; 29(2):119-28. http://dx.doi.org/10.1597/1545-1569(1992)029\%3C0118 :CSMBOC\%3E2.3.CO;2

Williams S, Schmidt R, Disselhorst-Klug C, Rau G. An upper body model for the kinematical analysis of the joint chain of the human arm. Journal of Biomechanics. 2006; 39(13):241929. PMid:16159659. http://dx.doi.org/10.1016/j. jbiomech.2005.07.023

\section{Authors}

